\title{
Are pharmacological randomised controlled clinical trials relevant to real-life asthma populations? A protocol for an UNLOCK study from the IPCRG
}

\author{
Karin Lisspers ${ }^{1}$, Pedro Teixeira ${ }^{2}$, Coert Blom ${ }^{3}$, Janwillem Kocks ${ }^{4,5}$, Björn Ställberg ${ }^{1}$, David Price ${ }^{6}$ and Niels Chavannes ${ }^{7}$ \\ npj Primary Care Respiratory Medicine (2016) 26, 16016; doi:10.1038/npjpcrm.2016.16; published online 14 April 2016
}

\section{INTRODUCTION}

Asthma has a high prevalence worldwide with a high incidence in primary care settings in many countries. ${ }^{1}$ It is by definition a variable disease with a broad spectrum of clinical phenotypes, in which management and treatment can be difficult. ${ }^{2-8}$ The aim of asthma treatment is optimal control of the disease, which according to Global Initiative for Asthma (GINA) guidelines implies both symptom control and prevention of exacerbations. ${ }^{1}$ Despite several treatment options, studies show that about half of the patients have poor asthma control., ${ }^{2,3}$ When asthma is not controlled, it decreases the quality of life, increases the risk of exacerbations and premature death and is a high cost for the society. ${ }^{2,3}$

There are concerns that current asthma treatment is based on research with subjects who are not representative of the patients seen in clinical practice. ${ }^{9}$ Guidelines for the management of asthma are usually developed on the basis of the available empirical evidence, and particular emphasis is placed on the conclusions of randomised controlled clinical trials (RCTs) and meta-analyses of RCTs that have been placed at the top of the evidence hierarchy. ${ }^{10}$ However, most RCTs have restricted inclusion criteria to obtain a high level of internal validity and usually recruit patients from secondary health-care settings. The external validity of RCTs, which provides evidence for major clinical guidelines, may be questioned if they are not representative of real-life populations in primary care. ${ }^{11-15}$ In the 2007 study by Travers et al, only 4\% (range $0-36 \%$ ) of participants with asthma in a population-based survey met the eligibility criteria to be included in 17 major RCTs cited in the GINA guidelines. ${ }^{14}$ The same study found that only $6 \%$ (range $0-43 \%$ ) of participants receiving asthma treatment also met the eligibility criteria. The proportion of patients with asthma from primary care settings that would be eligible for the major RCTs is unknown. If the proportion is similar to that found in the study by Travis et al., then the generalisability of the conclusions and the clinical relevance of major RCTs may be questionable, and they have not been improved in the past decade. There is a need to explore the external validity of pharmacological RCTs in primary care populations. The UNLOCK (Uncovering and Noting LongTerm Outcomes in COPD and asthma to enhance knowledge) project ${ }^{15}$ of the International Primary Care Respiratory Group
(IPCRG) covers a broad primary care population that may help clarify the external validity of these RCTs.

\section{AIMS AND OBJECTIVES}

The aim of this study is to determine whether the inclusion criteria for patients with asthma in the major RTCs supporting GINA guidelines are representative of real-life primary care populations with asthma. The study will address the following research questions:

1. What proportion of patients in primary care would be eligible for the major RCTs assessing patients at treatment step two heading for step three?

2. What are the clinical characteristics of these patients when compared with participants in major RCT studies?

\section{DISCUSSION}

Asthma is a highly prevalent disease worldwide with variability and a large range of phenotypes. ${ }^{1-8}$ The management and treatment of patients with asthma in primary care is a challenge, and many patients still suffer from poor asthma control. ${ }^{2}$ The major international clinical guidelines for the prevention and management of asthma are influenced by the empirical evidence and conclusions of RCTs. ${ }^{9-14}$ However, RCTs tend to be highly selective in terms of inclusion and exclusion criteria for people with asthma and may under-represent primary care populations with asthma. Smokers, for example, are usually excluded from registration RCTs assessing inhaled corticosteroids (ICS), as smoking is known to reduce the efficacy of ICS. ${ }^{16}$ Other common exclusion criteria are pregnancy, lactation, elderly patients and other chronic diseases such as ischaemic heart disease. A common inclusion criterion is a bronchodilator $\mathrm{FEV}_{1}$ reversibility of 12 or $15 \%$, which is not a frequent clinical sign in real-life asthma patients, and in the Travers study, 71 (or 76\%) of participants with asthma were excluded. ${ }^{14}$

RCTs are important in establishing the efficacy and short-term safety of new therapies, but there are limitations in evaluation of effectiveness of the therapies in the real world. ${ }^{17}$ The assessment

\footnotetext{
${ }^{1}$ Department of Public Health and Caring Science, Family Medicine and Preventive Medicine, Uppsala University, Uppsala, Sweden; ${ }^{2}$ ICVS/3B's - PT Government Associate Laboratory, Life and Health Sciences Research Institute (ICVS), School of Health Sciences, University of Minho, Braga, Portugal; ${ }^{3}$ Department of Primary and Community Care, Radboud University Nijmegen, Nijmegen, The Netherlands; ${ }^{4}$ Department of General Practice, University of Groningen, University Medical Center Groningen, Groningen, The Netherlands; ${ }^{5}$ GRIAC Research Institute Groningen, University of Groningen, University Medical Center Groningen, Groningen, The Netherlands; ${ }^{6}$ Academic Primary Care, Division of Applied Health Sciences, University of Aberdeen, Aberdeen, UK and ${ }^{7}$ Public Health and Primary Care, Leiden University Medical Center, Leiden, The Netherlands. Correspondence: K Lisspers (karin.lisspers@ltdalarna.se)
}

Received 21 November 2015; revised 13 January 2016; accepted 26 January 2016 
of the external validity of asthma RCTs is therefore needed to better understand the clinical relevance of their conclusions. There should be discussion on the need for effective studies, pragmatic trials and observational studies, as a complement to RCTs, to evaluate treatment outcomes in real-life clinical settings including the whole asthma population. The main weakness of these studies might be a lower internal validity, which needs to be addressed in the design of the studies. When developing guideline recommendations in the future, data from both efficacy and effectiveness studies should be evaluated with the strengths and weaknesses given. ${ }^{18}$

This study will provide estimates of the proportion of real-life primary care populations that are eligible for RCTs. It will also present descriptive characteristics of primary care patients compared with patients included in RCTs. This will present relevant information for the adequacy and use of GINA and other major guidelines in primary health-care settings. ${ }^{16-20}$ Previous findings suggest that the level of representation of the population with asthma ${ }^{14}$ and chronic obstructive pulmonary disease $(C O P D)^{13}$ in RCTs may be lower than desirable. This study can inform not only the development of future clinical practice guidelines ${ }^{17-20}$ but also the way asthma clinical trials are being designed and implemented. ${ }^{10}$ The study will tell us more about the patients who are not eligible for these major RCTs, and it may also provide new insights into why the control of asthma in many patients does not appear to improve in spite of the implementation of the treatment strategies that are recommended in guidelines.

\section{MATERIALS AND METHODS}

\section{Study design}

The study will use an observational design for comparing baseline characteristics of asthma patients in primary care databases with the inclusion criteria in the pharmacological RCTs that support major international guidelines (i.e., GINA).

Data collection and inclusion criteria

Data collection will involve two steps:

1. Step one will identify the major relevant RCTs used in GINA guidelines.

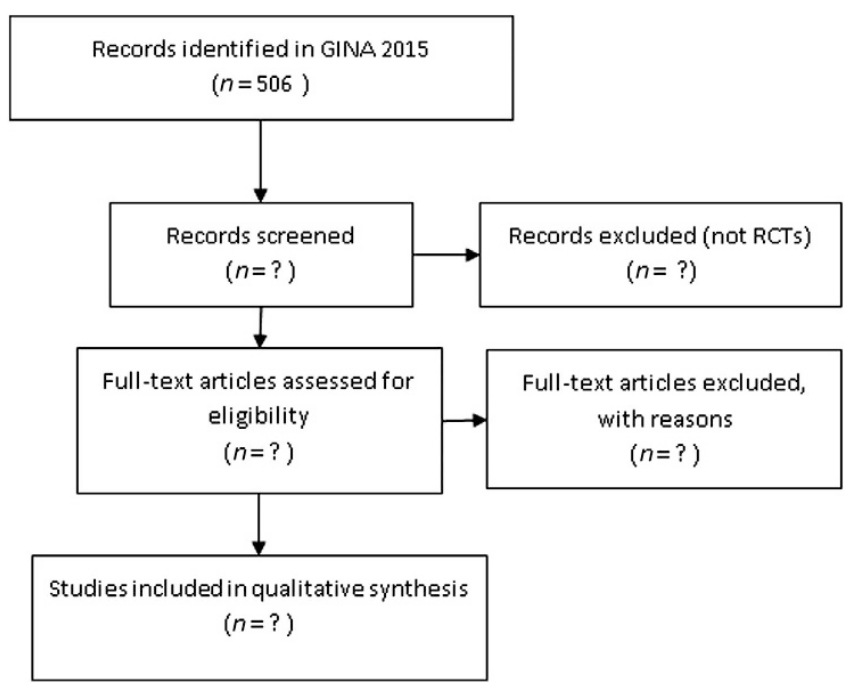

Figure 1. Flowchart of RCT identification process.
2. Step two will identify the primary care data sets that contain the required variables to assess eligibility for participation in the major RCTs.

In step one, a Systematic Review focusing the search on selected asthma international guidelines (i.e., GINA) will be conducted in order to identify all studies that fit the following criteria:

- Randomised controlled clinical trial

- Pharmacological treatment at GINA management step 2 heading for step 3

- RCT sample size $n>400$

- Other criteria (e.g., mainly adult population)

The systematic review will follow the PRISMA ${ }^{21}$ statement guidelines and follow the steps identified in Figure 1.

In step two, members of the IPCRG UNLOCK group will be invited to participate in the study with primary care data sets that include the variables listed in Table 1.

Participants identified in the data sets will remain anonymous. Patient confidentiality will be assured in the collection and merging of the data sets.

\section{Data analysis}

Data will be analysed according the defined criteria for the identification of RCTs. Statistical analysis of the data sets will provide summary descriptive statistics, means, measures of dispersion and proportions. The statistical analysis will focus on group classification values, and no individual statistical values will be computed or revealed.

Ethical approval

All included data sets will require approval by local primary care research ethics committees.

Table 1. List of variables for data set inclusion in the study

\begin{tabular}{|c|c|c|}
\hline Variables & Required & Optional \\
\hline $\begin{array}{l}\text { Age (>12 years) } \\
\text { Gender } \\
\text { Medication: ICS, LABA, SABA, combination, } \\
\text { Montelukast-(last } 3 \text { months) fixed combination } \\
\text { (ICS/LABA) }\end{array}$ & $\begin{array}{l}\sqrt{V} \\
\sqrt[V]{ }\end{array}$ & \\
\hline $\begin{array}{l}\text { One of: } \\
\text { Asthma control (GINA or ACQ or ACT) } \\
\text { QoL (miniAQLQ) }\end{array}$ & $\sqrt{ }$ & \\
\hline Smoking history: (never-former-current) & & $\sqrt{ }$ \\
\hline $\begin{array}{l}\text { Latest lung function assessment } \\
\mathrm{FEV}_{1} \% \text { of predicted } \\
\mathrm{FEV}_{1} \text { reversibilty } \\
\mathrm{FEV}_{1} / \mathrm{FVC} \text { (VC) ratio }\end{array}$ & & $\sqrt{ }$ \\
\hline $\begin{array}{l}\text { Allergy (pollen, pets, house dust mite) } \\
\text { Allergic rhinitis } \\
\text { Comorbidities heart disease (i.e., heart failure or } \\
\text { ischaemic heart disease) } \\
\text { Asthma control (i.e., according to GINA: last } \\
\text { week: daytime symptoms, night symptoms } \\
\text { rescue medication and exacerbations history, } \\
\text { courses of oral steroids history or ACQ or ACT) } \\
\text { QoL (i.e., miniAQLQ) }\end{array}$ & & $\begin{array}{l}\sqrt{ } \\
\sqrt{ } \\
\sqrt{ } \\
\sqrt{ }\end{array}$ \\
\hline $\begin{array}{l}\text { Abbreviations: ACQ, asthma control ouestionnaire; } \\
\text { test; ICS, inhaled corticosteroids; } L A B A \text {, long-acting } \beta \\
\text { mini quality of life questionnaire; QoL, quality of life } \\
\beta \text {-agonists. }\end{array}$ & e; SABA, & $\begin{array}{l}\text { na contro } \\
\text { miniAQLQ } \\
\text { lort-acting }\end{array}$ \\
\hline
\end{tabular}




\section{COMPETING INTERESTS}

JK, BS and NC are Associate Editors of npj Primary Care Respiratory Medicine, but were not involved in the editorial review of, nor the decision to publish this article. KL has received honoraria for educational activities and lectures from AstraZeneca, GlaxoSmithKline, Novartis, MEDA and Takeda, and has served on advisory boards arranged by MEDA and Novartis. BS has received honoraria for educational activities and lectures from AstraZeneca, Boehringer Ingelheim, GlaxoSmithKline, Novartis, MEDA and TEVA, and has served on advisory boards arranged by AstraZeneca, Novartis and Boehringer Ingelheim. DBP has Board Membership with Aerocrine, Almirall, Amgen, AstraZeneca, Boehringer Ingelheim, Chiesi, Meda, Mundipharma, Napp, Novartis and Teva. Consultancy: Almirall, Amgen, AstraZeneca, Boehringer Ingelheim, Chiesi, GlaxoSmithKline, Meda, Mundipharma, Napp, Novartis, Pfizer, Teva and Zentiva; grants/grants pending with UK National Health Service, British Lung Foundation, Aerocrine, AstraZeneca, Boehringer Ingelheim, Chiesi, Eli Lilly, GlaxoSmithKline, Meda, Merck, Mundipharma, Novartis, Orion, Pfizer, Respiratory. Effectiveness Group, Takeda, Teva and Zentiva; payments for lectures/speaking: Almirall, AstraZeneca, Boehringer Ingelheim, Chiesi, Cipla, GlaxoSmithKline, Kyorin, Meda, Merck, Mundipharma, Novartis, Pfizer, SkyePharma, Takeda and Teva; payment for manuscript preparation: Mundipharma and Teva; patents (planned, pending, or issued): AKL; payment for the development of educational materials: GlaxoSmithKline, Novartis; stock/stock options: shares in AKL that produces phytopharmaceuticals and owns $80 \%$ of Research in Real-Life and its subsidiary social enterprise Optimum Patient Care; received payment for travel/accommodations/meeting expenses from Aerocrine, Boehringer Ingelheim, Mundipharma, Napp, Novartis, and Teva; funding for patient enrollment or completion of research: Almirall, Chiesi, Teva and Zentiva; peer reviewer for grant committees: Medical Research Council (2014), Efficacy and Mechanism Evaluation programme (2012), HTA (2014); and received unrestricted funding for investigator-initiated studies from Aerocrine, AKL, Almirall, Boehringer Ingelheim, Chiesi, Meda, Mundipharma, Napp, Novartis, Orion, Takeda, Teva and Zentiva. The remaining authors declare no conflict of interest.

\section{FUNDING}

The IPCRG provided funding for this research project as an UNLOCK Group study for which the funding was obtained through an unrestricted grant by Novartis AG, Basel, Switzerland. Novartis has no role in study design, data collection and analysis, decision to publish or preparation of the manuscript. This study will include data from the Optimum Patient Care Research Database and is undertaken in collaboration with Optimum Patient Care and the Respiratory Effectiveness Group.

\section{REFERENCES}

1. The Global Asthma Report. Global Asthma Network: Auckland, New Zealand, 2014 http://www.globalasthmanetwork.org/publications/Global_Asthma_Report_2014.pdf. Accessed on September 2015.

2. Reddel, H. K., Sawyer, S. M., Everett, P. W., Flood, P. V., Peters, M. J. Asthma control in Australia: a cross-sectional web-based survey in a nationally representative population. Med. J. Aust. 202, 492-497 (2015).

3. Demoly, P. et al. Prevalence of asthma control among adults in France, Germany, Italy, Spain and the UK. Eur. Respir. Rev. 18, 105-112 (2009).

4. Mims, J. W. Asthma: definitions and pathophysiology. Int. Forum Allergy Rhinol. 5, S2-S6 (2015)
5. Sadowski, C. A., Cor, K., Cave, A. \& Banh, H. L. Administration technique and acceptance of inhaler devices in patients with asthma or COPD. Ann. Pharmacother. 49, 639-648 (2015).

6. van Boven, J. F., Trappenburg, J. C., van der Molen, T. \& Chavannes, N. H. Towards tailored and targeted adherence assessment to optimise asthma management. NPJ Prim. Care Respir. Med. 25, 15046 (2015).

7. Fischer, J., Wimmer, A. \& Mahlich, J. Medication adherence in asthma therapy--a structured review. Pneumologie 67, 406-414 (2013).

8. Sheehan, W. J. \& Phipatanakul, W. Difficult-to-control asthma: epidemiology and its link with environmental factors. Curr. Opin. Allergy Clin. Immunol. 15, 397-401 (2015).

9. Wong, G. W., Miravitlles, M., Chisholm, A. \& Krishnan, J. A. Respiratory guidelines -which real world? Ann. Am. Thorac. Soc. 11(Suppl 2): pp S85-S91 (2014).

10. Harbour, R. \& Miller, J. A new system for grading recommendations in evidence based guidelines. BMJ 323, 334-336 (2001).

11. Williams, B. A. Perils of evidence-based medicine. Perspect. Biol. Med. 53, 106-120 (2010).

12. Herland K., Akselsen J.-P., Skjønsberg O. H. \& Bjermer L. How representative are clinical study patients with asthma or COPD for a larger "real life" population of patients with obstructive lung disease?. Respir. Med. 99, 11-19 (2005).

13. Kruis, A. L. et al. Primary care COPD patients compared with large pharmaceutically-sponsored COPD studies: an UNLOCK validation study. PLOS ONE 9, e90145 (2014).

14. Travers, J. et al. External validity of randomised controlled trials in asthma: to whom do the results of the trials apply? Thorax 62, 219-223 (2007).

15. Chavannes, N. et al. UNLOCK: uncovering and noting long-term outcomes in COPD to enhance knowledge. Prim. Care Respir. J. 19, 408 (2010).

16. Roche, N. et al. Quality standards for real-world Research. Focus on observational database studies of comparative effectiveness. Ann. Am. Thorac. Soc. 11(Suppl 2): S99-S104 (2014).

17. Price, D. et al. Real-world research and its importance in respiratory medicine. Breathe (Sheff) 11, 26-38 (2015).

18. Price, D., Hillyer, E. \& van der Molen, T. Efficacy versus effectiveness trials: informing guidelines for asthma management. Curr. Opin. Allergy Clin. Immunol. 13, 50-57 (2013).

19. Lalloo, U. G. et al. Asthma programmes in diverse regions of the world: challenges, successes and lessons learnt. Int. J. Tuberc. Lung Dis. 15, 1574-1587 (2011).

20. Reddel, H. K. \& Levy, M. L. The GINA asthma strategy report: what's new for primary care? Npj Prim. Care Respir. Med. 25, 15050 (2015).

21. Moher D., Liberati A., Tetzlaff J., Altman D. G. The PRISMA Group Preferred reporting items for systematic reviews and meta-analyses: the PRISMA Statement. J. Clin. Epidemiol. 151, 264-269 (2009).

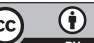

This work is licensed under a Creative Commons Attribution 4.0 International License. The images or other third party material in this article are included in the article's Creative Commons license, unless indicated otherwise in the credit line; if the material is not included under the Creative Commons license, users will need to obtain permission from the license holder to reproduce the material. To view a copy of this license, visit http://creativecommons.org/licenses/ by/4.0/ 